\title{
ANALISIS KESESUAIAN LAHAN UNTUK USAHA GARAM INDUSTRI DI WILAYAH PESISIR KABUPATEN PANGKAJENE DAN KEPULAUAN
}

\author{
Analysis Of Land Fitness For Industrial Salt Business in The Coastal Area \\ Pangkajene District and Islands \\ Oleh: \\ Mustakim ${ }^{1)}$, Muh. Kasnir' ${ }^{2}$, Abdul Rauf ${ }^{2)}$ \\ 1) Dinas Perikanan Kabupaten Pangkep Sulawesi Selatan \\ 2) Program Budidaya Perairan FPIK UMI Makassar \\ 3) Program Studi Ilmu Kelautan FPIK UMI makassar \\ Email : ams.anti.asli@gmail.com
}

Diterima: Tanggal 2 Januari 2019; Disetujui 31 April 2019

\begin{abstract}
The purpose of this study is to find suitable pond areas for salt ponds. Modeling in GIS, site selection studies are appropriate for industrial salt farms. Geographic Information System modeling can predict ponds that are appropriate and not appropriate for industrial salt ponds. The model used in this study is the index model. In Suharyadi and Danoedoro (2004) explained that index modeling involves the use of scores for each different category. this model can be applied to GIS Vector or raster. Overlaying maps involves arithmetic calculation processes, either amount, subtraction, multiplication or division. The index or score possessed by the new mapping unit on the derived map illustrates the combined conditions of various criteria used as the basis for decision making. The results of the analysis found that the area that was very suitable for salt ponds reached 1716.58 ha or 81.97\% of the area of ponds in Pangkep Regency. Areas that are not suitable for salt ponds reach 377.48 ha or reach $18.03 \%$. from pond area. . Fishponds suitable for industrial salt farms are found in areas close to the coastline.
\end{abstract}

Keywords; Analysis, Land Fitness, Industrial Salt, Industrial Salt Business

ABSTRAK

Tujuan penelitian ini mencari wilayah tambak yang sesuai untuk tambak garam. Pemodelan dalam SIG, dapat dilakukan kajian pemilihan lokasi (Site Selection) yang sesuai untuk tambak garam industri. Pemodelan Sistem Informasi geografis tersebut dapat mempredikasi tambak yang sesuai dan tidak sesuai untuk tambak garam industri. Model yang dipergunakan dalam penelitian ini adalah model indeks. Dalam Suharyadi dan Danoedoro (2004) menjelaskan bahwa pemodelan indeks melibatkan penggunaan skor untuk setiap kategori yang berbeda. model ini dapat diterapkan pada SIG Vektor maupun raster. Tumpang susun peta-peta melibatkan proses kalkulasi aritmatik, baik jumlah, pengurangan, perkalian atau pembagian. Indeks atau skor yang dimiliki satuan pemetaan baru pada peta turunan mengambarkan kondisi gabungan dari berbagai criteria yang dijadikan dasar pengambilan keputusan. Hasil analisis mendapatkan bahwa daerah yang sangat sesuaiuntuk tambak garam mencapai 1716,58 ha atau $81,97 \%$ dari luas tambak di Kabupaten Pangkep. Daerah yang kurang sesuai untuk tambak garam mencapai 377,48 ha atau mencapai $18,03 \%$. dari luas tambak. Daerah tambak yang sesuai untuk tambak garam industri terdapat pada daerah yang dekat dengan garis pantai.

Kata kunci; Analisis, Kesesuaian Lahan, Usaha Garam, Usaha Garam Industri

PENDAHULUAN

Pengertian SIG sendiri

merupakan pemrosesan data keruangan dalam bentuk pemrosesan data numerik dan data atribut (Farda dan Sudaryatno, 2004). Metode SIG yang dipergunakan 
dalam penelitian ini adalah pemodelan spasial. Suharyadi dan Danoedoro (2004) menjelaskan pemodelan spasial digunakan untuk memodelkan dunia nyata, dimaksudkan untuk menyelesaikan masalah lingkungan atau kewilayahan. Pemodelan ini berbagai variabel dipetakan secara digital dan disesuaikan sistem proyeksinya maupun koordinatnya dengan melibatkan aspek resolusi dan sistem klasifikasinya. Secara garis besar terdapat lima macam model dalam SIG yang digunakan untuk pemodelan lingkungan dan kewilayahan, yaitu : model biner, model indeks, model regresi, model proses, dan model jaringan.

\section{METODOLOGI}

Pemodelan dalam SIG, dapat dilakukan kajian pemilihan lokasi (site selection) yang sesuai untuk tambak garam induatri. Pemodelan Sistem Informasi geografis tersebut dapat memprediksi tambak yang sesuai, dan tidak sesuai untuk tambak garam industri. Model yang dipergunakan dalam penelitian ini adalah model indeks. Dalam Suharyadi dan Danoedoro (2004) menjelaskan bahwa pemodelan indeks melibatkan penggunaan skor untuk setiap kategori yang berbeda. Model ini dapat diterapkan pada SIG vektor maupun raster. Tumpang susun peta-peta melibatkan proses kalkulasi aritmatik, baik jumlah, pengurangan, perkalian atau pembagian. Indeks atau skor yang dimiliki satuan pemetaan baru pada peta turunan menggambarkan kondisi gabungan dari berbagai kriteria yang dijadikan dasar pengambilan keputusan.

\section{Jenis dan Sumber Data}

Data yang akan dikumpulkan dalam penelitian ini terdiri dari data primer dansekunder. Data primer bersumber dari Petani garam yang diperolehdengan melakukan pengamatan langsung di lapangan dan dengan wawancara langsung dengan pemangku kebijakan dan masyarakat setempat. Untuk melengkapi data hasil wawancara digunakan kuisioner yang bertujuan untuk mengetahui presepsi masyarakat mengenai Usaha Garamdengan kualitas garam industry serta pengembangannya. Data yang diperoleh dari kuisioner berupa data persepsi mengenai dimensi ekologi, dimensi ekonomi, dimensi sosial budaya, dan dimensi kelembagaan. 
Data sekunder diperoleh dari instansi terkait. Adapun data yang dikumpulkan berasal dari data-data hasil penelitian sebelumnya, data tentang peraturan pemerintah atau kebijakanan pemerintah mengenai Usaha garam serta data pendukung lainnya yang berkaitan dengan Usaha Garam rakyat. Adapun data sekunder yang dibutuhkan adalah : data fisik wilayah, data sosial ekonomi masyarakat diantaranya tingkat pendidikan, mata pencaharian, pendapatan, serta sarana dan prasarana.

\section{a. Teknik Penentuan Sampel}

Populasi ialah kelompok elemen yang lengkap, dimana kita tertarik untuk mempelajari atau menjadi objek penelitian (Kuncoro, 2003). Populasi dalam penelitian ini adalah pengarap garam/pelaku kegiatan pengaraman diKabupaten Pangkep yang betul betul menguasai cara produksi garam industri. berdasarkan data dari Dinas Perikanan Kabupaten Pangkep. Jumlah petani garam di kabupaten Pangkep sebanyak 682 orang. Penentuan jumlah sampel dari petani garam industri ditentukan dengan persamaan yang dikemukakan oleh (Slovin 1960, dalam Nuraeni 2012) Yakni :

$$
n=\frac{\mathrm{N}}{\mathrm{N} \cdot \mathrm{d} 2+1}
$$

Dimana: $\mathrm{n}=$ Sampel yang dicari

$$
\mathrm{N}=\text { Jumlah Populasi }
$$

D2 = Presisi yang ditetapka $(10 \%)$

$$
\mathrm{n}=628 / 628 .(10 \%)+1=38
$$

\section{Orang}

Berdasarkan Persamaan diatas, sampel yang akan diambil dikelompokan sebagai berikut :

a) Untuk petambak Garam Industri sebanyak $=32$ orang

b) Untuk Dinas Perikanan dan Penyuluh Perikanan masing Masing 3 Orang

Pengelompokan sampel diawali dengan asumsi bahwa proses usaha garam industri di wilayah Pesisir Kabupaten Pangkep pada umummnya dalah sama dari segi proses produksi garam industri misalnya bahan baku dan kondisi alam pada umummnya.

\section{b. Teknik Pengumpulan Data}

Data primer dikumpulkan secara intensif dengan menggunakan wawancaraterstruktur terhadap usaha garam industri, observasi dan dokumentasi di lokasi terpilih.Datasekunder diperoleh dengan melakukan studi literatur dan wawancara dengan pengelola usaha 
garam industri. Data tersebut dapat diperoleh dari dinas, lembaga atau instasi terkait dalampengelolaan garam seperti Dinas Perikanan, InstitusiPenelitian Perikanan, Universitas, Kantor Kelurahan atau Desa, Badan Pusat Statistik, dan lainlain.

Alat yang digunakan dalam penelitian ini adalah ; Komputer/ Laptop dan Printer, Software ArcGis, GPS, alat pengambilan sampel tanah dan Air, alat Ukur tanah dan air, Alat Tulis Kantor (ATK) untuk mencatat data hasil wawancara dan untuk mengisi daftar kuisioner, serta kamera digital untuk dokumentasi hasil kegiatan di lapangan. Bahan yang digunakan pada penelitian ini adalah Citra IKONOS Wilayah Kabupaten Pangkep yang didapatkan dari Geogle Eart, Peta Rupa Bumi Indonesia mencakup wilayah Kabupaten Pangkep skala $1: 25.000$.

Tahapan-tahapan dalam analisis data penginderaan jauh adalah sebagai berikut :

- Pra prosesing citra satelit. Pada tahapan ini hanya dilakukan koreksi geometri, yang bertujuan untuk meletakkan posisi obyek di citra sesuai dengan posisi sebenarnya dilapangan. Hasil pada proses awal ini adalah citra yang telah dikoreksi.

Interpretasi pengunaan lahan dilakukan dengan interpretasi citra dengan menggunakan metode digitasi pada citra IKONOS. Interpretasi pengunaan Hasil interpretase citra dilakukan pengecekan dilapangan untuk melihat keakurasiannya.

Penentuan lokasi sampling,lokasi sampling didasarkan pada karakteristik fisik dan lokasi yang sama pada tambak. Setelah penentuan lokasi sampling dilakukan pengambilan data baiksecara insitu $\left(\mathrm{pH},{ }^{0} \mathrm{Be}\right.$, pematang, ketinggian air, substrak dasar, gelengan dan dimensi gelengan). Selain itu diambil sampling air untuk pengukuran salinitas dan $\mathrm{pH}$ dan tanah untuk dilakukan pengukuran (Amoniak dan asam belerang)

- Hasil lapangan diinputkan ke dalam tribute peta dan pemudian dilakukan pemodelan dan scoring. Hasil scoring dilakukan klasifikasi untuk mendapatkan kesesuaian lahan tambak garam yang sesuai, dan tidak sesuai. 
Tabel. 1. Kriteria Kesesuaian Lahan Untuk Tambak Garam Industri

\begin{tabular}{|c|c|c|c|}
\hline \multirow[t]{2}{*}{ No } & \multirow{2}{*}{$\begin{array}{l}\text { Persayaratan } \\
\text { Pengunaan/karakterist } \\
\text { ik Lahan }\end{array}$} & \multicolumn{2}{|c|}{ Kelas Kesesuaian lahan } \\
\hline & & Sesuai (S) & Tidak Sesuai $(\mathrm{N})$ \\
\hline 1 & Amoniak (mg/l) & 0 & $>0,1$ \\
\hline 2 & Asam belerang (mg/l) & 0 & $>0.001$ \\
\hline 3 & $\mathrm{pH}$ & $7-8$ & $<6,>9$ \\
\hline 4 & Salinitas & $>30$ & $<30$ \\
\hline 5 & Pematang utama (m) & $\begin{array}{l}2-2,5, \text { ketinggian } 0,5 \\
\text { m diatas air pasang }\end{array}$ & $\begin{array}{c}<1,0 \text { ketinggian } 0,5 \mathrm{~m} \\
\text { diatas air pasang }\end{array}$ \\
\hline 6 & Pematang antara (m) & $\begin{array}{l}2-2,5, \text { ketinggian } 0,5 \\
\text { m diatas air pasang }\end{array}$ & $\begin{array}{c}<2,0 \text { ketinggian } 0,25 \mathrm{~m} \\
\text { diatas air pasang }\end{array}$ \\
\hline 7 & Ketinggian Air $(\mathrm{cm})$ & $5-10$ & $<5>10$ \\
\hline 8 & Dasar Tambak & $\begin{array}{l}\text { Pasir berlumpur atau } \\
\text { pasir }<20 \% \text { dengan } \\
\text { sedikit lumpur (mak } 2 \\
\mathrm{~cm} \text { ) }\end{array}$ & $\begin{array}{c}\text { Pasir berlumpur atau } \\
>20 \% \text { dengan sedikit } \\
\text { lumpur } 3 \mathrm{~cm} \text { ) }\end{array}$ \\
\hline 10 & $\begin{array}{l}\text { Kolam Penguapan } \\
\text { Evaporator }\left({ }^{\circ} \mathrm{Be}\right)\end{array}$ & 22 & $<22$ \\
\hline 11 & Kolam Air tua $\left({ }^{\circ} \mathrm{Be}\right)$ & $23-25$ & $<25$ \\
\hline 12 & $\begin{array}{l}\text { Meja garam } / \text { meja } \\
\text { kristalisasi }\left({ }^{\circ} \mathrm{Be}\right)\end{array}$ & 30 & $>30$ \\
\hline 13 & Dimensi gelengan & $\begin{array}{c}\text { Lebar atas } 50 \mathrm{~cm} \\
\text { tinggi minimal } 25 \mathrm{~cm} \text {, } \\
\text { kemiringan } 1: 1\end{array}$ & $\begin{array}{l}\text { Lebar }<40 \mathrm{~cm} \text {, tinggi } \\
<25 \mathrm{~cm} \text {, kemiringan } 1: 1\end{array}$ \\
\hline
\end{tabular}

Sumber : Firman Farid Muhsoni (2012, dimodifikasi oleh Mustakim, 2018

\section{c. Jenis dan Sumber Data}

Data yang akan dikumpulkan dalam penelitian ini terdiri dari data primer dansekunder. Data primer bersumber dari Petani garam yang diperolehdengan melakukan pengamatan langsung di lapangan dan dengan wawancara langsung dengan pemangku kebijakan dan masyarakat setempat. Untuk melengkapi data hasil 
wawancara digunakan kuisioner yang bertujuan untuk mengetahui presepsi masyarakat mengenai Usaha Garamdengan kualitas garam industry serta pengembangannya. Data yang diperoleh dari kuisioner berupa data persepsi mengenai dimensi ekologi, dimensi ekonomi, dimensi sosial budaya, dan dimensi kelembagaan.

Data sekunder diperoleh dari instansi terkait. Adapun data yang dikumpulkan berasal dari data-data hasil penelitian sebelumnya, data tentang peraturan pemerintah atau kebijakanan pemerintah mengenai Usaha garam serta data pendukung lainnya yang berkaitan dengan Usaha Garam rakyat. Adapun data sekunder yang dibutuhkan adalah : data fisik wilayah, data sosial ekonomi masyarakat diantaranya tingkat pendidikan, mata pencaharian, pendapatan, serta sarana dan prasarana.

\section{d. Teknik Penentuan Sampel}

Populasi ialah kelompok elemen yang lengkap, dimana kita tertarik untuk mempelajari atau menjadi objek penelitian (Kuncoro, 2003). Populasi dalam penelitian ini adalah pengarap garam/pelaku kegiatan pengaraman diKabupaten Pangkep yang betul betul menguasai cara produksi garam industri. berdasarkan data dari Dinas Perikanan Kabupaten Pangkep. Jumlah petani garam di kabupaten Pangkep sebanyak 682 orang. Penentuan jumlah sampel dari petani garam industri ditentukan dengan persamaan yang dikemukakan oleh (Slovin 1960, dalam Nuraeni 2012) Yakni :

$$
n=\frac{\mathrm{N}}{\mathrm{N} \cdot \mathrm{d} 2+1}
$$

Diman : $\mathrm{n}=$ Sampel yang dicari

$$
\mathrm{N}=\text { Jumlah Populasi }
$$

D2 = Presisi yang ditetapka $(10 \%)$

$\mathrm{n}=628 / 628 .(10 \%)+1=38$ Orang

Berdasarkan Persamaan diatas, sampel yang akan diambil dikelompokan sebagai berikut :

c) Untuk petambak Garam Industri sebanyak $=32$ orang

d) Untuk Dinas Perikanan dan Penyuluh Perikanan masing Masing 3 Orang

Pengelompokan sampel diawali dengan asumsi bahwa proses usaha garam industri di wilayah Pesisir Kabupaten Pangkep pada umummnya dalah sama dari segi proses produksi garam industri misalnya bahan baku dan kondisi alam pada umummnya. 
HASIL DAN PEMBAHASAN

Eksisting Tambak Garam di Kabupaten Pangkep

Hasil interpretasi citra satelit IKONOS mendapatkan bahwa luas tambak untuk usaha garam rakyat di wilayah pesisir kabupaten pangkajene dan kepulauan sebagai lokasi penelitian untuk usaha garam industri di wilayah pesisir kabupaten pangkajene dan Kepulauan yang meliputi Desa
Bontomanai, Kelurahan Pundata Baji di dan Kelurahan Borimasunggu di Kecamatan labakkang yang luas lahan mencapai 2.094,06 Ha. Penggunaan lahan tambak garam di Kecamatan labakkang yang tersebar di Desa Bontomanai dengan luas lahan 1.222.55 Ha, Kelurahan Pundata Baji dengan luas lahan 412,61 Ha dan Kelurahan Borimasunggu dengan luas lahan 458,891 Ha.

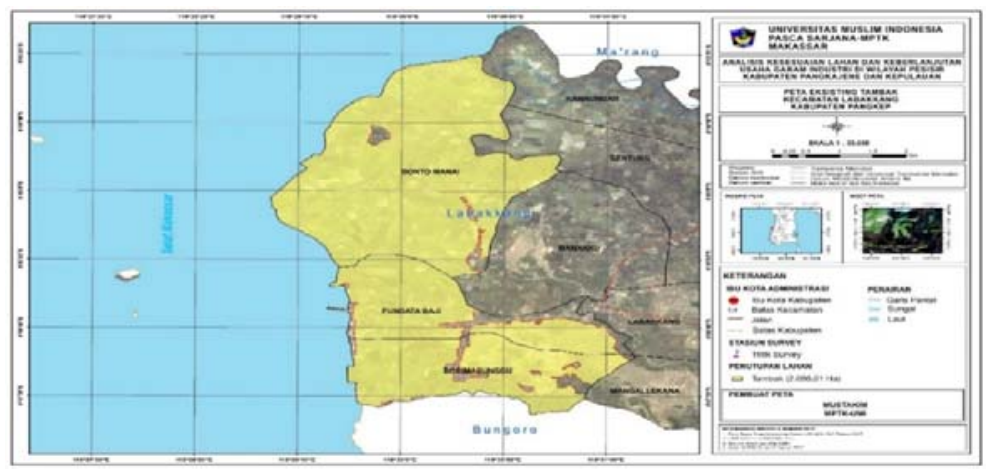

Gambar 2. Peta lahan tambak eksisiting hasil digitasi IKONOS

Luas dan penyebaran lahan luas wilayah penelitian dan Kelurahan garam pada wilayah penelitian yang Pundata Baji merupakan wilayah dibedakan berdasarkan Desa atau tambak garam yang paling sedikit Kelurahan adalah luasan tambak yaitu 412,618 Ha atau $19,71 \%$ dari garam paling luas terdapat pada Desa luas tambak garam keseluruhan. Bontomanai yang mencapai 1.222,55 Keseluruhan luasan ini masih ha atau $58,38 \%$ dari total luas wilayah termasuk tambak budidaya Ikan Penelitian.Luas lahan terluas kedua bandeng dan Udang di dalamanya adalah Kelurahan Borimasunggu (Gambar 2). seluas $458,892 \mathrm{Ha}$ atau $21,91 \%$ dari 
Tabel 2. Luastambak garam yang ada di Kecamatan Labakkang Kabupaten Pangkajene dan Kepulauan

\begin{tabular}{|c|c|c|c|}
\hline No & Desa/Kelurahan & Luas Lahan (Ha) & Luas Lahan (\%) \\
\hline 1 & Bontomanai & $1.222,55$ & 58,38 \\
\hline 2 & Pundata Baji & 412,61 & 19,71 \\
\hline 3 & Borimasunggu & 458,89 & 21,91 \\
\hline
\end{tabular}

Pada areal yang eksisting dan keamanan konsumen. Untuk itu sebagai areal tambak garam sebesar perlu dilakukan survey mengenai 2094,06 Ha merupakan areal yang telah kondisi lahan tambak garam utamanya dimanfaatkan atau pernah dimanfaatkan kandungan bahan pencemaran baik itu sebagai tambak garam. Areal tersebut berupa bahan organik maupun bahan merupakan areal tambak garam yang anorganik utamanya bahan logam berat. dikelolah secara tradisional yang Dari hasil analisis laboratorium sampel produktif dan usaha tambak garam tanah yang dilakukan dilaboratorium tersebut dilakukan dan dikelolah oleh tanah Politani Kabupaten Pangkajene masyarakat.

\section{A. Analisis Kesesuaian Lahan untuk Tambak Garam industri diwilayah pesisir kabupaten pangkep}

a. Kondisi Lahan tambak garam

Data mengenai kondisi lahan tambak garam baik lingkungan perairan maupun dasar tambak garam sangat menentukan teknis pengelolaan usaha dan Kepulauan untuk pengukuran parameter amoniak dan asam belerang serta pengukuran kualitas air seperti parameter salinita $\mathrm{pH}$ tanah dan air yang dilakukan langsung dilapangan selanjutnya untuk hasil uji laboratorium Parameter amoniak dan asam belerang serta pengukuran langsung dilapangan salinitas dan $\mathrm{pH}$ disaji pada tabel 3 berikut ini : garam industri serta kelayakan teknis

Tabel 3. Data Kualitas Air dan Tanah Pada Lahan Tambak Garam di wilayah pesisir Kabupaten Pangkajene dan Kepulauan

\begin{tabular}{|c|c|c|c|c|c|c|}
\hline Koordinat & Stasiun & $\begin{array}{c}\text { NH3 } \\
(\mathrm{PPM})\end{array}$ & $\begin{array}{c}\text { Sulfat } \\
(\mathrm{ppm})\end{array}$ & $\begin{array}{c}\mathrm{pH} \\
\text { Tanah }\end{array}$ & $\begin{array}{c}\mathrm{pH} \\
\text { air }\end{array}$ & SALINITAS \\
\hline
\end{tabular}




\begin{tabular}{|c|c|c|c|c|c|c|c|}
\hline$X$ & Y & & Amoniak & $\begin{array}{c}\text { Asam } \\
\text { Belerang }\end{array}$ & & & \\
\hline $\begin{array}{c}119^{\circ} 30^{\prime} \\
44.496^{\prime \prime} \mathrm{E}\end{array}$ & $\begin{array}{c}4^{\circ} 47^{\prime} \\
24.965^{\prime \prime} \mathrm{S}\end{array}$ & 1 & 3.01564 & 59.43 & 8 & 8 & $>40$ \\
\hline $\begin{array}{c}119^{\circ} 31^{\prime} \\
0.150^{\prime \prime} \mathrm{E}\end{array}$ & $\begin{array}{c}4^{\circ} 47^{\prime} \\
28.046^{\prime \prime} \mathrm{S}\end{array}$ & 2 & 8.96695 & 56.10 & 8 & 8 & $>40$ \\
\hline $\begin{array}{c}119^{\circ} 30^{\prime} \\
50.640^{\prime \prime} \mathrm{E}\end{array}$ & $\begin{array}{c}4^{\circ} 47^{\prime} \\
11.810^{\prime \prime} \mathrm{S}\end{array}$ & 3 & 1.37172 & 73.48 & 8 & 8 & $>40$ \\
\hline $\begin{array}{c}119^{\circ} 30^{\prime} \\
17.340^{\prime \prime} \mathrm{E}\end{array}$ & $\begin{array}{c}4^{\circ} 47^{\prime} \\
23.310^{\prime \prime} \mathrm{S}\end{array}$ & 4 & 2.71422 & 72.05 & 7 & 8 & $>40$ \\
\hline $\begin{array}{c}119^{\circ} 30^{\prime} \\
19.752^{\prime \prime} \mathrm{E}\end{array}$ & $\begin{array}{c}4^{\circ} 47^{\prime} 6.881^{\prime \prime} \\
\mathrm{S}\end{array}$ & 5 & 2.68498 & 73.48 & 7 & 8 & $>40$ \\
\hline $\begin{array}{c}119^{\circ} 31^{\prime} \\
1.760^{\prime \prime} \mathrm{E}\end{array}$ & $\begin{array}{c}4^{\circ} 46^{\prime} \\
50.390^{\prime \prime} \mathrm{S}\end{array}$ & 6 & 0.00000 & 75.38 & 8 & 8 & $>40$ \\
\hline $\begin{array}{c}119^{\circ} 29^{\prime} \\
57.742^{\prime \prime} \mathrm{E}\end{array}$ & $\begin{array}{c}4^{\circ} 47^{\prime} 8.724^{\prime \prime} \\
\text { S }\end{array}$ & 7 & 4.23299 & 79.43 & 7 & 8 & $>40$ \\
\hline $\begin{array}{c}119^{\circ} 31^{\prime} \\
36.171^{\prime \prime} \mathrm{E}\end{array}$ & $\begin{array}{c}4^{\circ} 46^{\prime} \\
44.177^{\prime \prime} \mathrm{S}\end{array}$ & 8 & 3.06531 & 67.29 & 8 & 8 & $>40$ \\
\hline $\begin{array}{c}119^{\circ} 29^{\prime} \\
45.980^{\prime \prime} \mathrm{E}\end{array}$ & $\begin{array}{c}4^{\circ} 47^{\prime} \\
35.380^{\prime \prime} \mathrm{S}\end{array}$ & 9 & 0.00000 & 73.71 & 8 & 8 & $>40$ \\
\hline $\begin{array}{c}119^{\circ} 29^{\prime} \\
41.010^{\prime \prime} \mathrm{E}\end{array}$ & $\begin{array}{c}4^{\circ} 47^{\prime} \\
25.390^{\prime \prime} \mathrm{S}\end{array}$ & 10 & 0.47536 & 63.71 & 7 & 8 & $>40$ \\
\hline $\begin{array}{c}119^{\circ} 29^{\prime} \\
35.541^{\prime \prime} \mathrm{E}\end{array}$ & $\begin{array}{c}4^{\circ} 46^{\prime} 1.560^{\prime \prime} \\
\mathrm{S}\end{array}$ & 11 & 0.00000 & 56.33 & 7 & 8 & $>40$ \\
\hline $\begin{array}{c}119^{\circ} 29^{\prime} \\
59.139^{\prime \prime} \mathrm{E}\end{array}$ & $\begin{array}{c}4^{\circ} 45^{\prime} \\
37.714^{\prime \prime} \mathrm{S}\end{array}$ & 12 & 0.00000 & 74.67 & 7 & 8 & $>40$ \\
\hline $\begin{array}{c}119^{\circ} 30^{\prime} \\
19.170^{\prime \prime} \mathrm{E}\end{array}$ & $\begin{array}{c}4^{\circ} 46^{\prime} \\
24.600^{\prime \prime} \mathrm{S}\end{array}$ & 13 & 6.24247 & 58.00 & 7 & 8 & $>40$ \\
\hline $\begin{array}{c}119^{\circ} 30^{\prime} \\
26.080^{\prime \prime} \mathrm{E}\end{array}$ & $\begin{array}{c}4^{\circ} 46^{\prime} \\
25.280^{\prime \prime} \mathrm{S}\end{array}$ & 14 & 5.73964 & 60.86 & 8 & 8 & $>40$ \\
\hline $119^{\circ} 29^{\prime}$ & $4^{\circ} 46^{\prime}$ & 15 & 0.00000 & 73.71 & 8 & 8 & $>40$ \\
\hline
\end{tabular}




\begin{tabular}{|c|c|c|c|c|c|c|c|}
\hline $58.130 " \mathrm{E}$ & $36.020 " \mathrm{~S}$ & & & & & & \\
\hline $\begin{array}{l}119^{\circ} 29^{\prime} \\
5.703^{\prime \prime} \mathrm{E}\end{array}$ & $\begin{array}{c}4^{\circ} 45^{\prime} \\
20.793^{\prime \prime} \mathrm{S}\end{array}$ & 16 & 8.00235 & 85.38 & 8 & 8 & $>40$ \\
\hline $\begin{array}{c}119^{\circ} 29^{\prime} \\
36.115^{\prime \prime} \mathrm{E}\end{array}$ & $\begin{array}{c}4^{\circ} 45^{\prime} 6.289^{\prime \prime} \\
\mathrm{S}\end{array}$ & 17 & 2.21822 & 59.19 & 8 & 8 & $>40$ \\
\hline $\begin{array}{c}119^{\circ} 30^{\prime} \\
12.039^{\prime \prime} \mathrm{E}\end{array}$ & $\begin{array}{c}4^{\circ} 44^{\prime} \\
34.134^{\prime \prime} \mathrm{S}\end{array}$ & 18 & 0.00000 & 42.05 & 8 & 8 & $>40$ \\
\hline $\begin{array}{l}119^{\circ} 31^{\prime} \\
8.702^{\prime \prime} \mathrm{E}\end{array}$ & $\begin{array}{c}4^{\circ} 44^{\prime} \\
42.192^{\prime \prime} \mathrm{S}\end{array}$ & 19 & 1.70023 & 69.67 & 8 & 8 & $>40$ \\
\hline $\begin{array}{c}119^{\circ} 30^{\prime} \\
43.361^{\prime \prime} \mathrm{E}\end{array}$ & $\begin{array}{c}4^{\circ} 44^{\prime} \\
10.776^{\prime \prime} \mathrm{S}\end{array}$ & 20 & 0.00000 & 67.05 & 7 & 8 & $>40$ \\
\hline $\begin{array}{c}119^{\circ} 30^{\prime} \\
38.108^{\prime \prime} \mathrm{E}\end{array}$ & $\begin{array}{c}4^{\circ} 43^{\prime} \\
41.870^{\prime \prime} \mathrm{S}\end{array}$ & 21 & 0.00000 & 46.81 & 7 & 8 & $>40$ \\
\hline $\begin{array}{c}119^{\circ} 30^{\prime} \\
28.670^{\prime \prime} \mathrm{E}\end{array}$ & $\begin{array}{c}4^{\circ} 45^{\prime} \\
57.586^{\prime \prime} \mathrm{S}\end{array}$ & 22 & 2.79781 & 39.67 & 7 & 8 & $>40$ \\
\hline $\begin{array}{c}119^{\circ} 30^{\prime} \\
42.629^{\prime \prime} \mathrm{E}\end{array}$ & $\begin{array}{c}4^{\circ} 45^{\prime} \\
31.267^{\prime \prime} \mathrm{S}\end{array}$ & 23 & 5.99482 & 63.95 & 7 & 8 & $>40$ \\
\hline $\begin{array}{c}119^{\circ} 30^{\prime} \\
23.520^{\prime \prime} \mathrm{E}\end{array}$ & $\begin{array}{c}4^{\circ} 44^{\prime} \\
57.060^{\prime \prime} \mathrm{S}\end{array}$ & 24 & 0.00000 & 52.29 & 8 & 8 & $>40$ \\
\hline $\begin{array}{c}119^{\circ} 30^{\prime} \\
2.440^{\prime \prime} \mathrm{E}\end{array}$ & $\begin{array}{c}4^{\circ} 45^{\prime} 8.080^{\prime \prime} \\
\mathrm{S}\end{array}$ & 25 & 0.88346 & 64.67 & 8 & 8 & $>40$ \\
\hline $\begin{array}{l}119^{\circ} 29^{\prime} \\
8.354^{\prime \prime} \mathrm{E}\end{array}$ & $\begin{array}{c}4^{\circ} 44^{\prime} \\
53.670^{\prime \prime} \mathrm{S}\end{array}$ & 26 & 0.00000 & 46.81 & 8 & 8 & $>40$ \\
\hline $\begin{array}{c}119^{\circ} 29^{\prime} \\
42.898^{\prime \prime} \mathrm{E}\end{array}$ & $\begin{array}{c}4^{\circ} 44^{\prime} \\
15.889^{\prime \prime} \mathrm{S}\end{array}$ & 27 & 0.00000 & 32.76 & 8 & 8 & $>40$ \\
\hline $\begin{array}{c}119^{\circ} 30^{\prime} \\
2.222^{\prime \prime} \mathrm{E}\end{array}$ & $\begin{array}{c}4^{\circ} 43^{\prime} \\
37.514^{\prime \prime} \mathrm{S}\end{array}$ & 28 & 3.06228 & 63.71 & 8 & 8 & $>40$ \\
\hline $\begin{array}{c}119^{\circ} 30^{\prime} \\
26.260^{\prime \prime} \mathrm{E}\end{array}$ & $\begin{array}{c}4^{\circ} 45^{\prime} 3.090^{\prime \prime} \\
\mathrm{S}\end{array}$ & 29 & 5.60276 & 51.81 & 8 & 8 & $>40$ \\
\hline $\begin{array}{c}119^{\circ} 30^{\prime} \\
14.170^{\prime \prime} \mathrm{E}\end{array}$ & $\begin{array}{c}4^{\circ} 46^{\prime} \\
56.110^{\prime \prime} \mathrm{S}\end{array}$ & 30 & 4.33399 & 53.95 & 7 & 8 & $>40$ \\
\hline
\end{tabular}


b. Sebaran Salinitas

\section{Hasil pengukuran parameter} kualitas air dalam hal ini salinitas dan $\mathrm{pH}$ di Wilayah penelitian sebagaimana di sajikan pada gambar 5 dibawah ini menunjukan hasil dari parameter salinitas air yang berada dilokasi penelitian sebagai bahan baku dalam pembuatan garam menunjukan secara umum sebaran salinitas seragam disemua lokasi penelitian. Hal ini disebabkan karena pengambilan sampel kualitas air dilakukan pada musin kemarau atau pada saat pengelolaan garam berlangsung. Selain itu sungai pemasok air laut sebagai bahan baku pengaraman salingberdekatan satu sama lain sehingga salinitas relatif sama atau seragam di semua lokasi. Atau dengan kata lain muara sungai yang satu dengan yang lainnya saling berdekat disamping itu lahan pengaraman salin bersambung antara desa bontomanai, kelurahan Pundata baji dan Kelurahan pundata baji. Bahkan sungan yang berada diwilayan pengaraman tersebut saling nyambung antara yang satu dengan yang lainnya

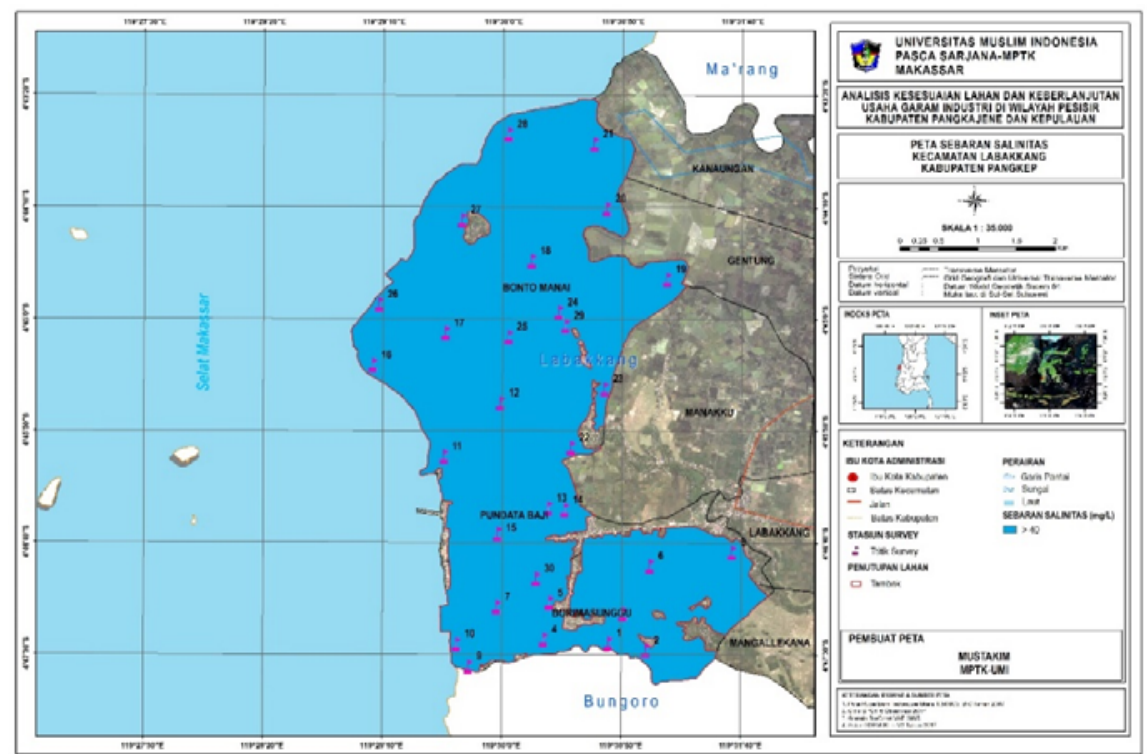

Gambar 3. Peta Sebaran Salinitas untuk tambak garam industri. 
c. Sebaran Amoniak

Sebaran amoniak pada gambar 4 menunjukkan hasil dari pengukuran amoniak (NH3) yang berada dilokasi penelitian terlihat di titik 2 pada kelurahan Borimasunggu kisaran pada 5 - 7 ml.lt hal ini disebabkan karena wilayah tersebut di kelilingi pohon mangrove di samping itu lahan tersebut berada dekat dengan wilayah pengunungan dan hutan/ perkebunan masyarakat. titik 13,14 pada kelurahan Pundata Baji kisaran 3-4 mg.lt pada titik ini berada di dekat pemukiman masyarakat dimana buangan limbah organik dari rumah tangga berpengaruh pada kandungan amoniak di wilayah tersebut dan titk 16 pada desa Bontomanai terdapat kondisi kandungan amoniak yang tinggi yang itu kisaran $5-7 \quad \begin{array}{llll}\text { ml.lt hal ini } & -\end{array}$ disebabkan karena wilayah tersebut berada pada hutan manggrove pengaruh pembusukan dari daun mangrove di samping itu cara budidaya yang dilakukan menggunakan bahan organik seperti pemumupukan berlebihan. Sedangkan pada daerah lain hampir merata di seluruh wilayah adapun kandungan amoniak yang ada pada lokasi penelitian ini disebabkan karena penggunaan bahan organik pada saat proses pembudiyaan ikan yang dilakukan oleh pemilik tambak pada musim penghujan karena lahan garam yang ada di wilayah pesisir kabupaten pangkajene dan kepulauan merupakan daerah petambak udang dan ikan pada musin penghujan.

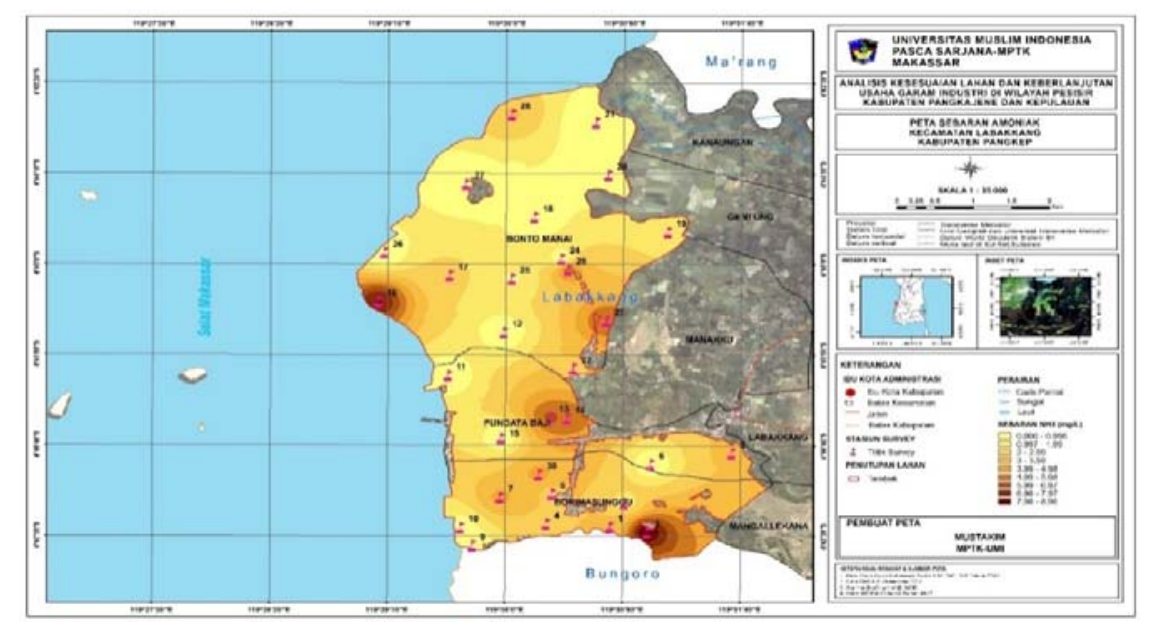

Gambar 4. Peta Sebaran Amoniak 
d. Sebaran Asam Belerang

Nitrat tidak bersifat toksik bagi organisme akuatik. Konsumsi air yang mengandung kadar nitrat yang tinggi akan menurunkan kapasitas darah untuk mengikat oksigen, terutama pada bayi yang berumur kurang dari lima bulan. Keadaan ini dikenal sebagai methemoglobinemia atau blue baby disease, yang mengakibatkan kulit bayi berwarna kebiruan (Effendi, 2003).

Nitrat pada konsentrasi yang tinggi dapat menstimulasi pertumbuhan ganggang yang tak terbatas, sehingga air kekurangan oksigen terlarut yang menyebabkan kematian ikan. NO3dapat berasal dari buangan industri bahan peledak, pupuk, cat dan sebagainya. Kadar nitrat secara alamiah biasanya agak rendah; namun kadar nitrat dapat menjadi lebih tinggi sekali pada air tanah di daerah-daerah yang diberi pupuk yang mengandung nitrat. Kadar nitrat tidak boleh melebihi 10 mg NO3/L (di Indonesia dan A.S) (Alaerts, 1984).

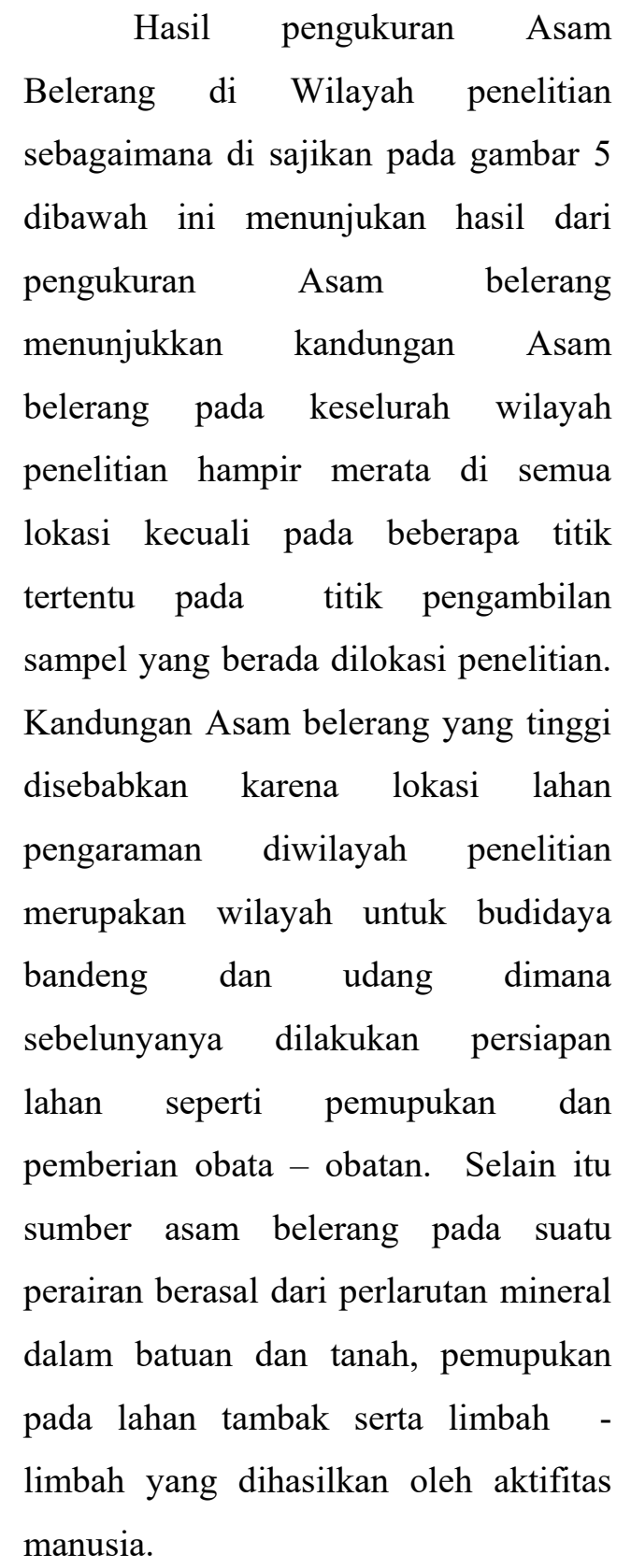

Hasil pengukuran Asam sebagaimana di sajikan pada gambar 5 dibawah ini menunjukan hasil dari pengukuran Asam belerang Asam penelitian hampir merata di semua lokasi kecuali pada beberapa titik sampel yang berada dilokasi penelitian. Kandungan Asam belerang yang tinggi disebabkan karena lokasi lahan pengaraman diwilayah penelitian merupakan wilayah untuk budidaya sebelunyanya dilakukan persiapan lahan seperti pemupukan dan pemberian obata - obatan. Selain itu perairan berasal dari perlarutan mineral dalam batuan dan tanah, pemupukan pada lahan tambak serta limbah manusia. 


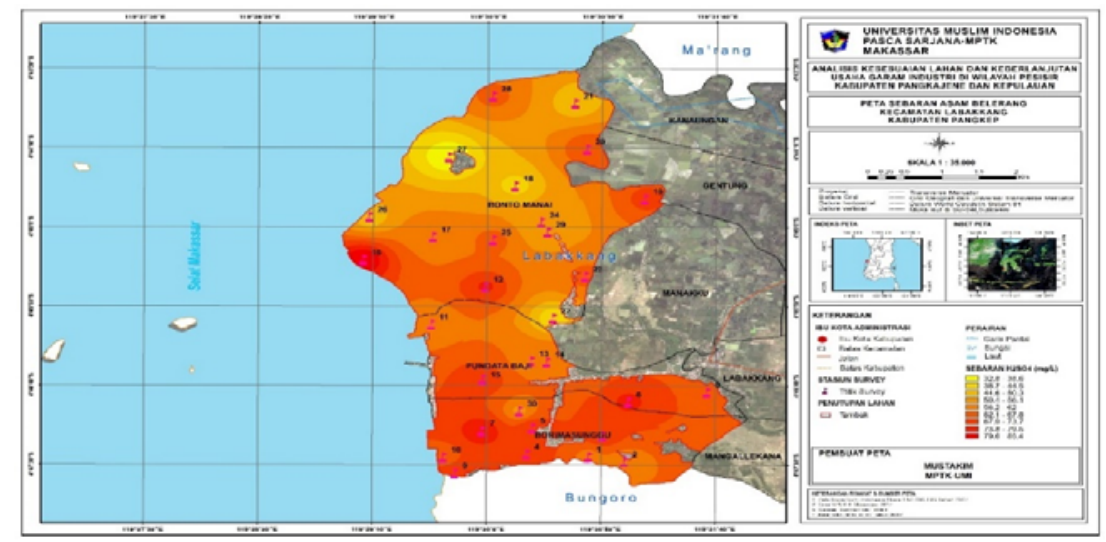

Gambar 5. Peta Sebaran Asam Belerang

Keseuaian Lahan Usaha Garam kabupaten pangkajene dan Kepulauan Industri diwilayah Pesisir Kabupaten dapat dilihat pada gambar 6 dan tabel 4 . Pangkajene dan Kepulauan

Kesesuaian lahan untuk usaha garam industri dapat digunakan dalam perencanaan untuk mengidentifikasi wilayah potensial pengembangan usaha garam industri dimana usaha garam industri merupakan hal baru dan juga membantu mengatur pengembangan usaha garam rakyat di tempat yang sudah ada. Pengembangan garam industri yang tidak tepat bisa mengakibatkan tingginya discounting rate pada penggunaan sumber daya alam dan eksploitasi diluar daya dukung. (GESAMP,2001). Hasil analisis kesesuaian lahan usaha garam industri di wilayah pesisir kabupaten pangkajene dan Kepulauan didapatkan daerah yang sesuai untuk lahan tambak garam industri mencapai 1716,58 ha atau $81,97 \%$ dari luas lahan tambak garam di wilayah pesisir kabupaten pangkajene dan Kepulauan.Sedangkan lahan yang tidak sesuai untuk lahan tambak garam industri mencapai 377,481 ha atau mencapai 18,03 \%. dari luas lahan tambak garam . Sedangkan hasil analisis pada setiap desa dan kelurahan dapat dilihat pada Tabel 4 .

Hasil analisis kesesuaian lahan usaha garam industri di wilayah pesisir 
Tabel 4.Hasil analisis kesesuaian lahan tambak garam industri pada setiap Desa dan Kelurahan diwilayah pesisir kabupaten pangkajene dan kepulauan.

\begin{tabular}{|l|l|l|l|l|}
\hline No & Desa/ Kelurahan & $\begin{array}{l}\text { Klasifikasi Kesesuaian } \\
\text { tambak garam }\end{array}$ & $\begin{array}{l}\text { Luas Lahan } \\
(\mathrm{Ha})\end{array}$ & $\begin{array}{l}\text { Luas Ha } \\
(\%)\end{array}$ \\
\hline & Bontomanai & Sesuai & $1.037,480$ & 84,87 \\
\hline & Pundata Baji & Tidak Sesuai & 185,075 & 15,13 \\
\hline & & Sesuai & 358,288 & 86,83 \\
\hline & Borimasunggu & Sesuai & 54,330 & 13,17 \\
\hline & & Tidak sesuai & 320,815 & 69,91 \\
\hline
\end{tabular}

Sumber : Hasil Analisis Peta,2018

Hasil analisis menunjukkan 2.094,06 Ha. Dari lahan tersebut bahwa lahan tambak yang sesuai untuk merupakan lahan yang telah tambak garam industri ada pada daerah dimanfaatkan atau pernah dimanfaatkan yang dekat dengan garis pantai atau pun sebagai tambak garam. Lahan tersebut sungai, hal ini sangat dimungkinkan merupakan lahan tambak masyarakat karena sumber air untuk tambak garam yang dikelolah secara tradisional. Dari industri adalah air laut. Sedangkan total 2.094,06 Ha wilayah yang pernah lahan tambak yang tidak sesuai untuk dimanfaatkan sebagai tambak garam garam industri berada pada daerah yang kini hanya tersisa 355,90 Ha (37 \%) dekat dengan wilayah pemukimanan lahan yang masih dimanfaatkan sebagai atau daerah persawahan hal ini disebabkan karena pengaruh air tawar yang masih kuat di akibatkan oleh kegiatan pertanian atau persawahan di musin kemarau ( padi Gaduh). Selain itu lahan tambak yang baru dibuka atau dahulunya lahan sawah yang di ubah menjadi tambak. Dimana sumbet air asin berasal dari sumur bor.

Pada areal yang eksisting sebagai lahan tambak garam sebesar tambak garam yang produktif. Dinas Perikanan Kabupaten Pangkajene dan Kepuluan melalui program pengembangan usaha garam rakyat (PUGAR) telah memberikan bantuan kepada 4 Kelompok petambak garam rakyat yang mempunyai luas 78,65 ha sampai pada tahun 2018 dan tahun 2019 di rencanakan 6 kelompok dengan luas 100 ha untuk pengusaha garam industri. 


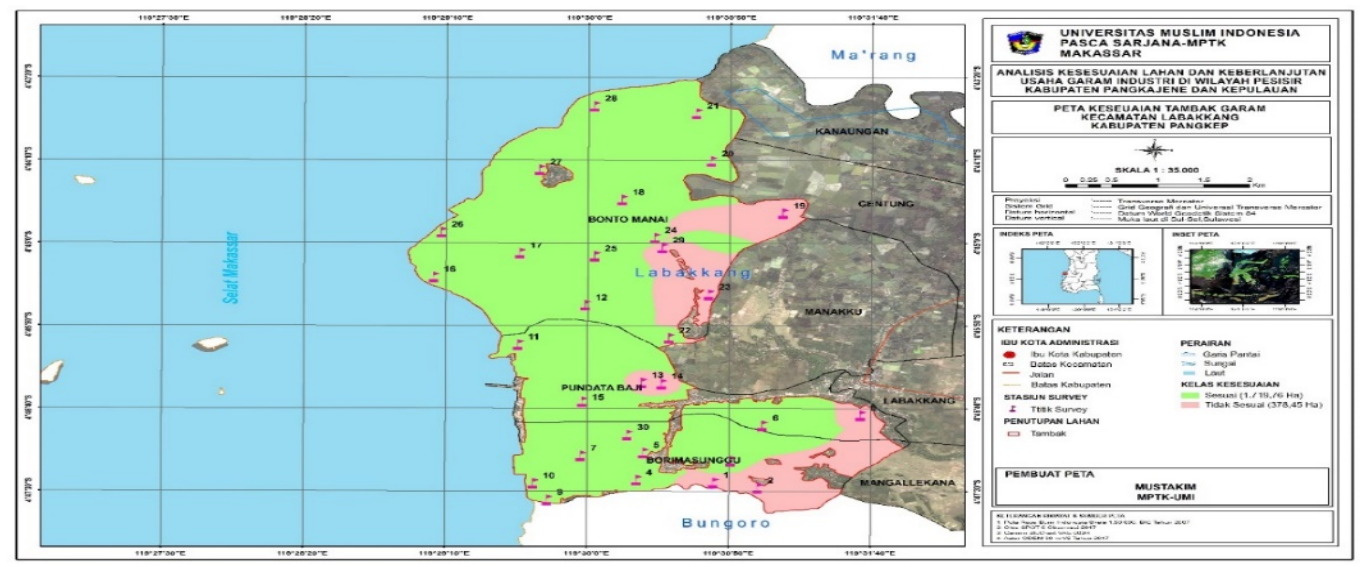

Gambar 6.Peta kesesuaian lahan untuk tambak garam hasil analisis data.

\section{KESIMPULAN}

1. Hasil analisis kesesuaian lahan untuk usaha tambak garam industri diwilaya pesisir Kabupaten Pangkajene dan Kepulauan menghasilkan luas tambak yang sesuai untuk tambak garam industri seluas $1.716,583$ ha $(81,97 \%)$, dan yang tidak sesuai untuk tambak garam industri mencapai 377,481 ha $(18,03 \%)$.

2. usaha garam industri di wilayah Pesisir Kabupaten Pangkajene dan Kepulauan masuk dalam katagori berkelanjutan dengan nilai indeks keberlanjutan masing-masing dimensi yaitu dimensi ekologi $(56,96)$ merupakan tingkat keberlanjutan Kategori cukup dimensi Ekonomi (62,92) merupakan tingkat keberlanjutan Kategori cukup dimensi sosial $(40,72)$ merupakan tingkat keberlanjutan Kategori Kurang dan dimensi Hukum dan kelembagaan merupakan tingkat keberlanjutan Kategori baik.

\section{SARAN}

1. Dari kesimpulan diatas, maka saran dari penelitian yaitu dalam pengelolaan usaha garam industri kedepannya dilakukan berdasarkanlahan yang dikategorikan sesuai 
2. Dari kesimpulan diatas, maka saran dari peneliti yaitu perlu perhatian lebih dari stakeholder dalam hal ini pemerintah baik pusat, provinsi, maupun daerah pada aspek Ekologi, Ekonomi sosial budaya untuk status keberlanjutan Usaha Garam Industri diwilayah Pesisr Kabupaten Pangkajene dan Kepulauan.

\section{UCAPAN TERIMA KASIH}

Penulis mengucapkan terima kasih kepada Pemerintah Kabupaten Pangkep yang telah memberikan izin melanjutkan studi.

\section{DAFTAR PUSTAKA}

Alaerts, G. dan Santika,S.S. 1984. Metoda Penelitian Air. Usaha Nasional. Surabaya.

Aris, Kabul. 2011. Pedoman Garam. Dirjen KP3K, Kementerian Kelautan dan Perikanan Republik Indonesia. Jakarta.

Assauri, Sofjan. (1993), "Interorganizational Process Dalam Pembinaan Pengusaha Ekonomi Lemah", Manajemen dan Usahawan Indonesia, no.6, tahun XXII, Juni, h. 21-26.
Anomsari, A dan Setyaningrum, R (2012).Implementasi model pemberdayaan UKM batik dalam upaya mengangkat kearifan local batik di Semarang. Hibah Bersaing.

Cotton dan Wilkinson. 1989. Kimia Anorganik Dasar. Cetakan pertama. UI- Press. Jakarta

Drajat, dan Widyaiswara Memilih lokasi Tambak Garam, artikel no. 171. BPPP Tegal

Effendi H. 2003. Telaah kualitas air bagi pengelolaan sumber daya dan lingkungan perairan. Kanisius. Yogyakarta.

Dinas Kelautan dan Perikanan Pangkep, 2016. Laporan Akhir Program Pengembangan Usaha Garam Rakyat. Satker Dinas Kelautan dan Perikanan Kabupaten Pangkep.

Fauzi, A, 2004, Ekonomi Sumber Daya Alam dan Lingkungan. Teori dan Aplikasi Gramedia Pustaka Utama. Jakarta.

Mahida, U.N. 1984. Pencemaran Air Dan Pemanfaatan Limbah Industri. Cetakan pertama. C.V. Rajawali. Jakarta.

Muhsoni,F 2012, Kesesuaian lahan tambak Garam Menggunakan Sistem Informasi Geografis di Kabupaten Sampang. Program studi Ilmu Kelautan Fakultas Pertanian. Universitas Tronojoyo Madura.

Hidayat, R. 2011, Rancang Bangun Alat Pemisah Garam dan Air Tawar Dengan Menggunakan 
Energi Matahari, Departemen Ilmu dan Teknologi Kelautan Fakultas Perikanan dan Ilmu Kelautan Institut Pertanian Bogor (Skripsi).

Ibrahim, 2016, Evaluasi Keberlanjutan Usaha Garam Rakyat di Kecamatan Bangkala Kabupaten Jenepoto, Program Pasca Sarjana. UMI. Makssar (Tesis)

Kompas.com. Tanggal akses 26 September 2012. Garam sesuai standart mutu. Predeep (2013). Make the most of your energy. International Seminar of Industrial and Management.

Kuncoro, 2003. Metode Riset untuk Bisnis dan Ekonomi. Jakarta. Erlangga.

Kristi, A. L., Taslim, C.M., Soetrisnanto, D. 2013, Rekristalisasi Garam Rakyat dari Demak untuk Mencapai Garam Industri, Jurnal Teknologi Kimia dan Industri, Vol. 2 No 3 Tahun 2013, hal. 217-225,

Nuraeni 2012, Analisis Statistik dan Data spasial. Jakarta

PT. Garam Persero(2006).Upaya perbaikan kualitas garam.

Poerwadi. B.S 2016. Petunjuk teknis Penyaluran bantuan Pemerintah, Dirjen Penegelolaan Ruang Laut. Kementrian kelautan dan Perikanan. Jakarta

Pitcher dan Preikshot, 2001. RAPFISH A Rapid Appraisal Technique to Evaluate The Sustainability Status Of Fisheries.Fisherie
Centre, University Of British Coulombia.

Purnomo A., Taryono H., Nasution Z., \& Hartono T.T. 2002. Analisis Rapfish Perikanan Selat Sunda (Laporan Teknis). Pusat Riset Wilayah Laut dan Sumberdaya Non Hayati. Badan Riset Kelautan dan Perikanan. Departemen Kelautan dan Perikanan. Jakarta.

Purbani (2010). Proses pembentukan kristalisasi garam. Dinas kelautan dan perikanan.

Rochwulaningsih, $\quad$ Y. 2010, Marginalisasi Garam Rakyat, Penerbit: CV Madina Semarang.

Rochwulaningsih, Y., Utama, M.P. 2013 Tipologi Sosiokultural Petambak Garam di Indonesia, Jilid 1. Penerbit: UNDIP Press.

Rosnah, Y (2013). Innovation ini manufacturing for sustainable growth.International Seminar of Industrial and Management.48

Suprijono, H (2008). Perancangan pengukur $\mathrm{CO} 2$ menggunakan mikrokontroler.

Sarjani, 2011. Cuaca dan Penguapan, Kumba Jember

Widayat, 2009, Production of Industry Salt with SedimentationMicrofiltration Process:Optimazation of Temperature and Concentration by Using Surface Response Methodology, Jurnal TEKNIK Vol. 30 No. 1 Tahun 2009, ISSN 0 